\title{
Space Shuttle Ascent Flight Design Process: Evolution and Lessons Learned
}

\author{
Bret A. Picka ${ }^{1}$ \\ United Space Alliance, Houston, TX 77058 \\ Christopher B. Glenn ${ }^{2}$ \\ NASA Johnson Space Center, Houston, TX 77058
}

The Space Shuttle Ascent Flight Design team is responsible for defining a launch to orbit trajectory profile that satisfies all programmatic mission objectives and defines the ground and onboard reconfiguration requirements for this high-speed and demanding flight phase. This design, verification and reconfiguration process ensures that all applicable mission scenarios are enveloped within integrated vehicle and spacecraft certification constraints and criteria, and includes the design of the nominal ascent profile and trajectory profiles for both uphill and ground-to-ground aborts. The team also develops a wide array of associated training, avionics flight software verification, onboard crew and operations facility products. These key ground and onboard products provide the ultimate users and operators the necessary insight and situational awareness for trajectory dynamics, performance and event sequences, abort mode boundaries and moding, flight performance and impact predictions for launch vehicle stages for use in range safety, and flight software performance. These products also provide the necessary insight to or reconfiguration of communications and tracking systems, launch collision avoidance requirements, and day of launch crew targeting and onboard guidance, navigation and flight control updates that incorporate the final vehicle configuration and environment conditions for the mission.

Over the course of the Space Shuttle Program, ascent trajectory design and mission planning has evolved in order to improve program flexibility and reduce cost, while maintaining outstanding data quality. Along the way, the team has implemented innovative solutions and technologies in order to overcome significant challenges. A number of these solutions may have applicability to future human spaceflight programs.

One area of difficulty has been offering the Program the flexibility that it desires. The Space Shuttle is an incredibly capable vehicle, making possible a wide variation in payload configurations and mission objectives. This can pose a challenge, especially for human missions. For example, it is necessary to provide flight crews with pre-flight training, and this drives designs to be completed well in advance of the launch date. Often, mission requirements will change between this initial design and flight, and launches can slip. The Ascent Flight Design team has implemented processes much closer to launch which allow for late updates to ground and onboard assets at minimal cost.

Another challenge has been the management of a large volume of fundamental technical change, such as the evolution of ascent nominal and abort trajectory and flight software capabilities, improvements required to increase program flexibility, and the ever-present challenge to increase payload to orbit. The Ascent Flight Design team has implemented

\footnotetext{
${ }^{1}$ Aerospace Engineer, Initialization Load Manager, Flight Design and Dynamics, 600 Gemini Ave, USH-482L

${ }^{2}$ Aerospace Engineer, Flight Dynamics Division - Ascent Analysis, 2101 NASA Parkway, DM44
} 
processes to ensure the impacts and implementation of such changes are properly coordinated amongst a variety of stakeholders.

Another focus has been the sustaining engineering required to maintain quality in a time of cost reductions and content additions. The Ascent Flight Design team has implemented rigorous process control on its procedures and software tools to ensure quality. In addition, the team has expanded its breadth of responsibility to include items such as the programassigned requirements ownership of key ascent guidance, navigation and onboard display flight software principal functions and initialization data.

The Space Shuttle Ascent Flight Design process has evolved with a significant increase in scope and content over the life of the program. The team has encountered and overcome obstacles that any other organization performing trajectory design for human missions are likely to encounter. The track record of outstanding quality, timeliness, and cost reductions points to a number of lessons learned which may be useful in shaping future, similar processes.

Copyright (C) 2010 by United Space Alliance, LLC. These materials are sponsored by the National Aeronautics and Space Administration under Contract NNJ06VA01C. The U.S. Government retains a paid-up, nonexclusive, irrevocable worldwide license in such materials to reproduce, prepare, derivative works, distribute copies to the public, and perform publicly and display publicly, by or on behalf of the U.S. Government. All other rights are reserved by the copyright owner. 


\title{
Space Shuttle Ascent Flight Design Process: Evolution and Lessons Learned
}

\author{
Bret A. Picka, ${ }^{1}$ \\ United Space Alliance, LLC, Houston, TX 77058 \\ Christopher B. Glenn ${ }^{2}$ \\ NASA Johnson Space Center, Houston, TX 77058
}

The Space Shuttle Ascent Flight Design team is responsible for defining a launch to orbit trajectory profile that satisfies all programmatic mission objectives and defines the ground and onboard reconfiguration requirements for this high-speed and demanding flight phase. This design, verification and reconfiguration process ensures that all applicable mission scenarios are enveloped within integrated vehicle and spacecraft certification constraints and criteria, and includes the design of the nominal ascent profile and trajectory profiles for both uphill and ground-to-ground aborts. The team also develops a wide array of associated training, avionics flight software verification, onboard crew and operations facility products. These key ground and onboard products provide the ultimate users and operators the necessary insight and situational awareness for trajectory dynamics, performance and event sequences, abort mode boundaries and moding, flight performance and impact predictions for launch vehicle stages for use in range safety, and flight software performance. These products also provide the necessary insight to or reconfiguration of communications and tracking systems, launch collision avoidance requirements, and day of launch crew targeting and onboard guidance, navigation and flight control updates that incorporate the final vehicle configuration and environment conditions for the mission.

Over the course of the Space Shuttle Program, ascent trajectory design and mission planning has evolved in order to improve program flexibility and reduce cost, while maintaining outstanding data quality. Along the way, the team has implemented innovative solutions and technologies in order to overcome significant challenges. A number of these solutions may have applicability to future human spaceflight programs.

One area of difficulty has been offering the Program the flexibility that it desires. The Space Shuttle is an incredibly capable vehicle, making possible a wide variation in payload configurations and mission objectives. This can pose a challenge, especially for human missions. For example, it is necessary to provide flight crews with pre-flight training, and this drives designs to be completed well in advance of the launch date. Often, mission requirements will change between this initial design and flight, and launches can slip. The Ascent Flight Design team has implemented processes much closer to launch which allow for late updates to ground and onboard assets at minimal cost.

Another challenge has been the management of a large volume of fundamental technical change, such as the evolution of ascent nominal and abort trajectory and flight software capabilities, improvements required to increase program flexibility, and the ever-present

\footnotetext{
${ }^{1}$ Aerospace Engineer, Flight Design \& Dynamics Department - Integration, 600 Gemini Ave, USH-482L

${ }^{2}$ Aerospace Engineer, Flight Dynamics Division - Ascent Analysis, 2101 NASA Parkway, DM44

1

American Institute of Aeronautics and Astronautics

Placeholder for Copyright statement.
} 
challenge to increase payload to orbit. The Ascent Flight Design team has implemented processes to ensure the impacts and implementation of such changes are properly coordinated amongst a variety of stakeholders.

Another focus has been the sustaining engineering required to maintain quality in a time of cost reductions and content additions. The Ascent Flight Design team has implemented rigorous process control on its procedures and software tools to ensure quality. In addition, the team has expanded its breadth of responsibility to include items such as the programassigned requirements ownership of key ascent guidance, navigation and onboard display flight software principal functions and initialization data.

The Space Shuttle Ascent Flight Design process has evolved with a significant increase in scope and content over the life of the program. The team has encountered and overcome obstacles that any other organization performing trajectory design for human missions are likely to encounter. The track record of outstanding quality, timeliness, and cost reductions points to a number of lessons learned which may be useful in shaping future, similar processes.

\section{Introduction}

$\mathrm{T}$ HE Ascent Flight Design (AFD) team has made significant contributions to the success of the Space Shuttle Program (SSP). This paper will describe and explore some of the challenges the team has encountered throughout the 135 Space Shuttle missions, and some of the strategies used to overcome them. It will also briefly outline additional lessons learned based on the AFD experience.

\section{Moving the work as late as possible}

The Space Shuttle was an incredibly capable vehicle in the sense that it could accommodate a very wide variety of missions. Orbital inclination, orbital altitude, propellant loads, and mass properties such as longitudinal center of gravity (CGx), Orbiter and overall integrated vehicle weights, and launch environment could vary dramatically from mission to mission, and each of these factors could have a significant influence on the no-fail ascent and ascent/entry abort trajectory design and design dependent trajectory and ground systems products. As a result, it was important to perform a detailed trajectory design for each new mission.

\section{A. The Base Template}

The SSP utilized several different generic templates to guide and schedule the flight preparation process. Key milestones pertaining to the ascent flight design from a typical template used late in the Program, called the "base" template, are shown in Table 1.

Table 1: Key milestones from the base template

\begin{tabular}{|l|l|l|}
\hline Milestone & Schedule tie & $\underline{\text { Description }}$ \\
\hline Mission baselining milestone & $\begin{array}{l}\text { Launch minus } \\
\text { (L-) } 378 \text { days }\end{array}$ & $\begin{array}{l}\text { A mission is considered formally baselined after it is } \\
\text { added to the Flight Definition and Requirements } \\
\text { Directive (FDRD; NSTS-07700 Volume III) }\end{array}$ \\
\hline $\begin{array}{l}\text { Trajectory Design Data Package } \\
\text { (TDDP) delivery }\end{array}$ & L-303 days & $\begin{array}{l}\text { TDDP contains key information describing the mission } \\
\text { profile and vehicle configuration }\end{array}$ \\
\hline $\begin{array}{l}\text { Flight Operations Panel (FOP) } \\
\text { meeting }\end{array}$ & L-288 days & $\begin{array}{l}\text { Meeting sets the groundrules and constraints to be used } \\
\text { in the trajectory and Initialization Load (I-Load) design }\end{array}$ \\
\hline I-Load Submit & L-233 days & Values for all I-Loads are submitted to the Space Shuttle \\
\hline
\end{tabular}




\begin{tabular}{|l|l|l|}
\hline & L-210 days & $\begin{array}{l}\text { All I-Load values for the mission are approved; the } \\
\text { values will be incorporated into the mission Flight } \\
\text { Software (FSW) in downstream processes }\end{array}$ \\
\hline I-Load Approval & L-127 days & $\begin{array}{l}\text { Final step in the process to configure the SMS and MCC } \\
\text { for mission-specific use }\end{array}$ \\
\hline $\begin{array}{l}\text { Shuttle Mission Simulator (SMS) } \\
\text { and Mission Control Center (MCC) } \\
\text { Load Releases }\end{array}$ & L-126 days & $\begin{array}{l}\text { Shuttle Mission Simulator (SMS) and Mission Control } \\
\text { Center (MCC) are ready; crew and flight controller } \\
\text { training can begin }\end{array}$ \\
\hline Ready-for-training milestone & \multicolumn{2}{|l}{} \\
\hline
\end{tabular}

The seven week period between the FOP meeting and the I-Load Submit milestone represented the time when AFD was performing its trajectory design and determining appropriate values for each of the Initialization Loads (ILoads) for which it was responsible. During these seven weeks, AFD was on the critical path of the overall flight preparation process. On any given mission, roughly 1,650 AFD-owned I-Load values were designed or selected, then verified, in dependent order. For perspective, this represents $\sim 16 \%$ of the $\sim 10,050$ I-Loads that were submitted for the reconfiguration of the flight software (FSW) mass memory for a single Space Shuttle mission, and more importantly represents a high percentage of the mission-to-mission unique trajectory design parameter updates. ILoads that were planned for the ascent nominal (no-fail) mission were designed and verified first. Next, I-Loads that were planned for the ascent intact abort trajectories were designed and verified in parallel, followed by contingency abort I-Load verification for key representative trajectories. Finally, onboard display I-Loads for both ascent nominal and abort scenarios were designed and verified last.

AFD I-Load design and verification involved a thorough examination. Automated tools were developed to check a wide array of SSP certification envelopes and constraints. Extensive numbers of trajectory cases were run where it was appropriate to do so, considering such factors as iterations on variables like guidance targets, systems constraints and criteria, abort performance boundaries, Space Shuttle Main Engine (SSME) failure points in the engine-out window, landing site, and SSME failed configuration (sequential or simultaneous).

Work in AFD continued after I-Load Submit to supply key technical and facility data to multiple customers across the country, including preparation of data to support training and real-time operations in the SMS and MCC. Additional data products were prepared to support customers internal to the SSP such as the flight Software Production Facility (SPF) and customers external to the SSP such as the Air Force/45 ${ }^{\text {th }}$ Space Wing (Range Safety).

As the schedule in Table 1 illustrates, the core ascent I-Load design was essentially complete about seven months prior to launch, in order to support mission-specific crew and flight controller training activities that began about four months prior to launch. However the I-Loads and associated trajectory products, being sensitive to changes in mission parameters such as launch environment, mass properties and propellant loadings, were frequently reassessed throughout the template as driving changes to the mission definition baseline were made. Often, to address constraint or criteria margin violations or to improve constraint margin, and to protect against further mission requirements changes or launch slips, these reassessments resulted in the need to redeliver data products and/or ILoads to incorporate the mission definition changes.

\section{B. Template improvement: Flight Operations Reinvention and ISS Standardization}

Recognizing that frequent design reassessments and product redeliveries were a cost and resource driver, process improvements were made. One of the most fundamental improvement efforts was called the Flight Operations Reinvention ("Reinvent") initiative. Reinvent was primarily active in the years 1998 to 2002 and was in direct support of an SSP initiative to "Reinvent processes/standards to increase manifest flexibility." Reinvent emerged at a goals and objectives meeting conducted by the SSP Manager in April 1998, and was the term used to categorize the last two levels of the "7 Levels of Change" i.e., Level 6 (Different - Do things that haven't been done) and Level 7 (Impossible - Do things that can't be done). At that meeting, a "change example" was given of moving the 
baseline milestone when a flight and cargo is approved in the Flight Definition and Requirements Directive (FDRD) from 12 months to 7 months prior to launch. SSP approval of the flight in the FDRD indicates that flight production can start. By the time Reinvent efforts were considered, the SSP had flown nearly 100 missions. Equivalent to the flight rate leading up to the launches of STS-61C and STS-51L/Challenger in January 1986, the Space Shuttle flight rate once again peaked at 10 flights flown between the launch of STS-70 on 6/27/1995 and launch of STS-78 on 6/20/1996. Processes being utilized then evolved out of a development program and were generally based on experience from expendable vehicle programs. At the element and sub-element level, processes were honed and improved. New processes were added, and others were modified as the SSP evolved. As a result, mission related processes were revised that had not been evalulated based on what was most operationally effective across all elements. Up to that point, processes lacked flexibility in handling dynamic manifests, higher flight rates, changes to baselined mission requirements, and hardware modifications. Maintaining and increasing SSP flexibility had been a significant challenge while upgrading aging vehicles and facilities, incorporating safety modifications, and ensuring manned access to space under tight budget constraints. The Reinvent vision was to preserve a unique capability and provide safe and reliable access to space, revitalize the SSP as a foundation for future agency endeavours, enable increased availability of Shuttle launch services, expand program flexibility through process enhancement and modern technology, and provide launch services that meet or exceed the customer's requirements for safety, performance, schedule and cost. As such, SSP goals and Reinvent objectives and strategies were tightly linked.

Figure 1 below provides a simplified overview of SSP mission processes affected by the Reinvent effort. The AFD work discussed in this paper is largely contained in the top line labeled "Flight Design." As one can see, AFD's work is only one component of the overall process.

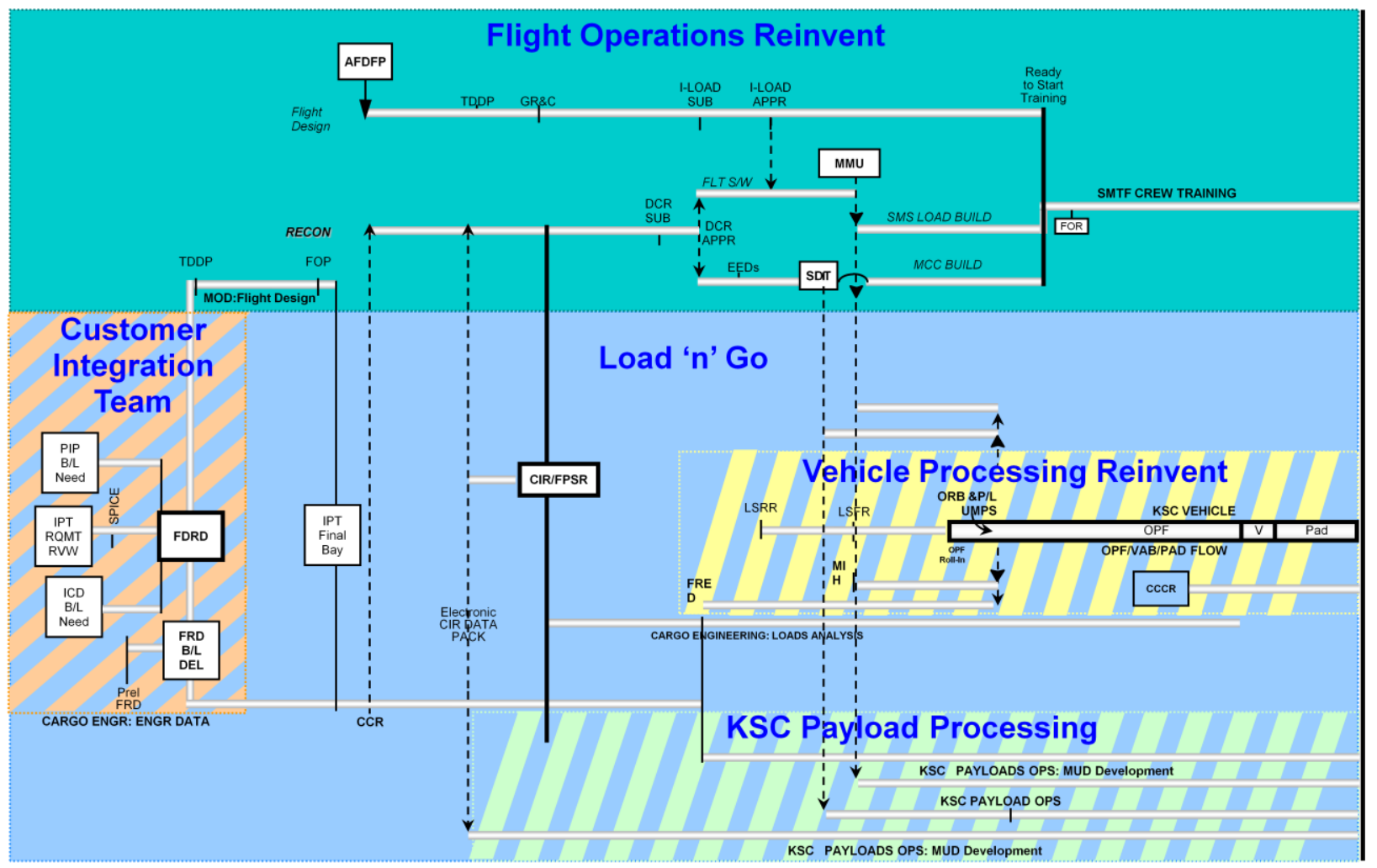

Figure 1: Flight Operations Reinvent Overview (CY 2000)

Specifically applicable to ascent/entry trajectory design processes, the reinvent effort sought changes to flight operations processes, tools, and work content such that the 12-month base template could be replaced with a 7- or 8month template, depending on the mission complexity and whether a similar mission had been recently designed. 
One component of Reinvent was called ISS Standardization, which sought to rearrange the template by removing training support products from the critical path by using standardized I-Loads and data products for missions to the International Space Station (ISS). These standardized I-Loads and products were to be used for generic crew and flight controller training. Later in the template, after all major manifest and mission requirements had been finalized, the mission specific ascent (and entry) designs could be completed. Delaying the ascent / entry designs closer to launch would reduce the probability of late changes requiring reassessments and rework.

The result of ISS Standardization was a new template, which delayed the ascent / entry I-Load designs. Key milestones of this new "ISS Standardization" template are shown in Table 2. The corresponding schedule ties from the old "base" template are also shown for comparison purposes.

Table 2: Key milestones from the ISS Standardization and Base templates

\begin{tabular}{|l|l|l|}
\hline$\underline{\text { Milestone }}$ & $\underline{\text { Schedule }- \text { ISS Standardization }}$ & Schedule - Base \\
\hline $\begin{array}{l}\text { Trajectory Design Data Package } \\
\text { (TDDP) delivery }\end{array}$ & L-198 days & L-303 days \\
\hline Flight Ops Panel (FOP) meeting & L-178 days & L-288 days \\
\hline I-Load Submit & L-128 days & L-233 days \\
\hline I-Load Approval & L-105 days & L-210 days \\
\hline $\begin{array}{l}\text { Shuttle Mission Simulator (SMS) } \\
\text { and Mission Control Center (MCC) } \\
\text { Load Releases }\end{array}$ & L-29 days & L-127 days \\
\hline \begin{tabular}{l} 
Ready-for-training milestone \\
\hline
\end{tabular} & L-28 days & L-126 days \\
\hline
\end{tabular}

As illustrated in Table 2, the ready-for-training milestone was delayed by 14 weeks (98 days) from L-126 days on the base template to L-28 days on the ISS Standardization template. This allowed the start of the ascent / entry designs, represented by the FOP milestone, to be delayed by more than 15 weeks (110 days) from L-288 days to L178 days. So while mission-specific ascent / entry training was not eliminated entirely, it was significantly delayed. This had the desired effect of reducing ascent product rework, since the overall mission profile had nearly 4 extra months to mature before the design was started.

\section{Process improvement: Just-in-time Flight Design}

Another component of Reinvent was called Just-in-time Flight Design (JITFD). The JITFD project was implemented with the belief and slogan "Do it once, get it right." Previous US human spaceflight programs had similar such beliefs as can be seen in Figure 2 with the Project Mercury stamp that was key to the then new manned flight awareness program, and the Project Gemini motivational poster that includes the slogan "Do it right...the first time."
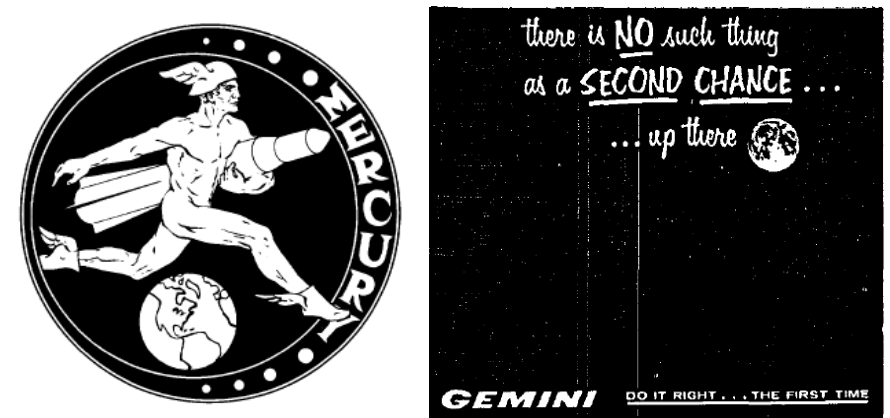

Figure 2: Manned Flight Awareness: Mercury Stamp, Gemini Motivational Poster

5

American Institute of Aeronautics and Astronautics

Placeholder for Copyright statement. 
JITFD was worked in conjunction with ISS Standardization, and focused on creating a more efficient flight design process by reducing the number of internal hand-offs, redundant quality assurance (QA) steps, and duplication of efforts that had crept into the system over the duration of the SSP. JITFD resulted in significant structural improvements to the flight design process, including the introduction of a method to pre-select off-the-shelf I-Load values to start with the best starting point as the basis of the design effort. After a transition from legacy computer systems using main frame centralized computing facilities to the more powerful and versatile client/server network by 1992, the team also took further advantage of parallel processing capabilities across the mission planning system to process a high number of trajectory scan iterations for nominal ascent, ascent/entry abort and External Tank (ET) entry trajectories. In some cases, intensive efforts that were performed on ascent abort trajectory design and performance iteration sub-processes had been reduced from what was 12 weeks early in the program to only a few days thus taking these off the critical path. Other process changes were made which allowed the overall 7-week ILoad design period to be completed in no more than 5 weeks, a $28 \%$ reduction in process cycle time. These process improvements also allowed much quicker technical assessments and support of fast-track analyses to explore generic and mission-specific options for the Space Shuttle Program. Figure 3 below provides an overview of the Reinvent project roadmap, showing key initiatives across all mission processes including the JITFD project.

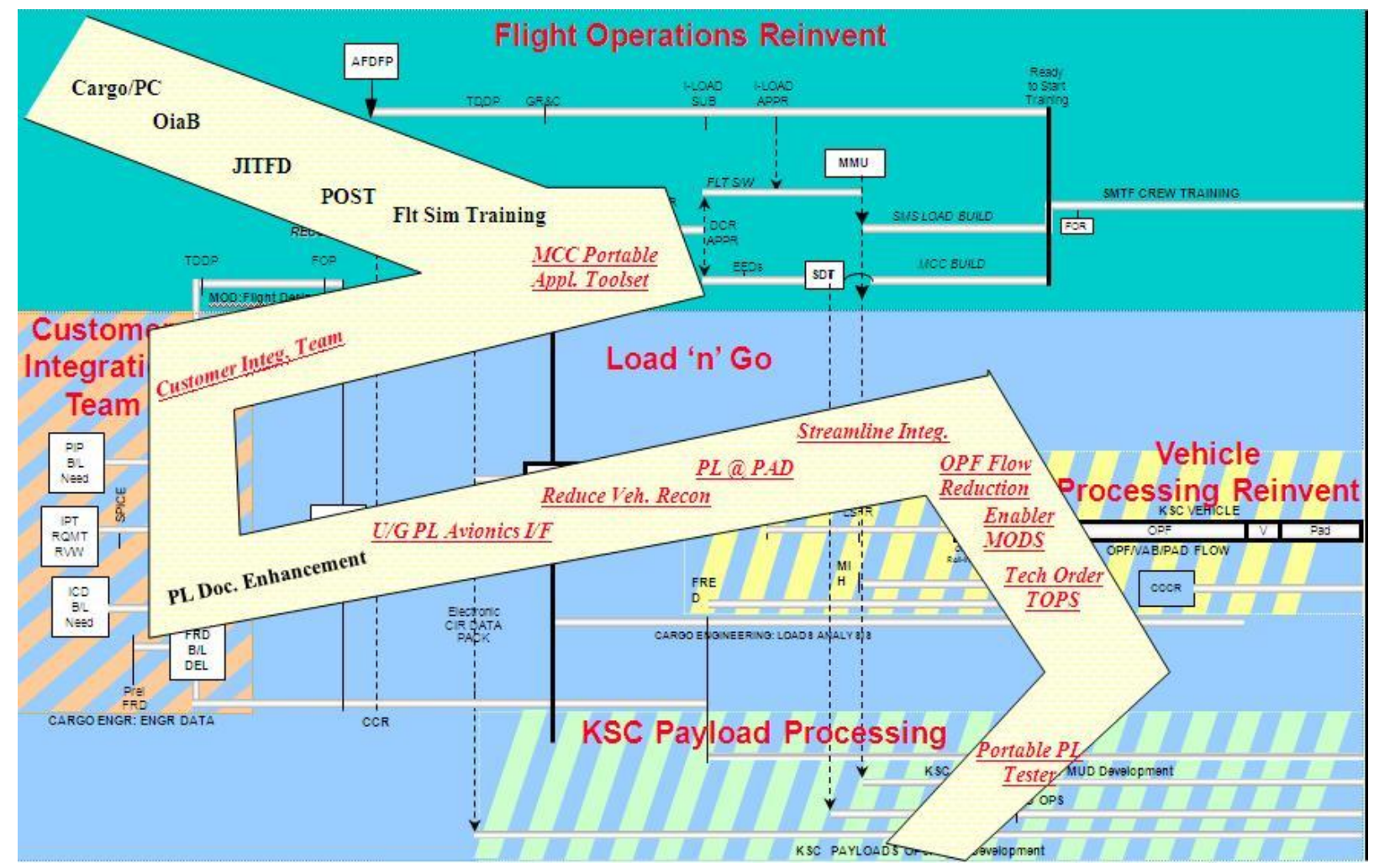

Figure 3: Flight Operations Reinvent Project Roadmap

\section{Process improvement: Expanded GNC parameter uplink capabilities}

I-Load "uplinks" are used to overwrite I-Load values resident in the FSW with a new value. For the ascent flight phase, uplinks were used on launch day, shortly before liftoff, to reset the FSW with applicable launch targeting parameters that had been recalculated for the actual launch date and time.

For much of the SSP duration, ascent-related I-Load uplinks were extremely limited. Due to the cost of implementation and cost/benefit implications, only a small subset of the $\sim 10,050$ I-Loads were available for uplink to the Primary Avionics Software System (PASS) and Backup Flight System (BFS) during prelaunch operations. For more than the first half of the 30-year Shuttle program, initial capabilities for ascent GNC parameter uplinks were primariliy limited to the nominal ascent trajectory especially the ascent GNC uplinks on day-of-launch for the 
first stage pitch and yaw attitude profile, measured winds, SSME throttle bucket, orbital plane steering targets and Orbital Maneuvering System (OMS) insertion burn targets. However, ascent I-Load uplink capabilities were strategically expanded beginning with Operational Increment (OI)-26 (incremental releases of space shuttle FSW were designated by the OI number), which introduced the ability to improve ascent performance by burning the OMS engines during second stage. I-Loads controlling the burn duration, as well as I-Loads controlling OMS burns for Abort To Orbit (ATO) aborts during the same time frame, were uplinkable. With OI-28, the capability was added to uplink I-Loads related to second stage nominal and aborts scenarios, specifically integrated vehicle and Orbiter guidance masses, SSME throttle level limits, and sequencing I-Loads to control abort Return-to-Launch-Site (RTLS) and Transatlantic Abort Landing (TAL) dumps. Finally, with OI-29, the capability was added to uplink additional I-Loads controlling functionality such as the nominal Main Engine Cut-Off (MECO) velocity and flight path angle targets and key guidance and sequencing parameters supporting the integrated ascent/entry design for the RTLS, TAL and uphill aborts.

By the first flight using OI-29 flight software (STS-110, which launched on 4/08/2002), modifications to flight software and ground systems resulted in the ability to uplink a comprehensive set of ascent GNC I-Loads that were especially sensitive to late manifest changes. Since the I-Loads could be uplinked directly to the vehicle on launch day, they could be redesigned much closer to launch as compared to the planned I-Load Submit milestone which significantly improved SSP flexibility.

\section{E. Process improvement: Late design cycle}

Prior to expanding the uplinkable I-Loads, the paradigm was to assess each mission configuration change as it was approved. If an issue was discovered, and I-Load values needed to be updated, an "I-Load Patch" was required. An I-Load Patch involved formally submitting the new I-Load values for independent engineering verification, and then having the FSW organization build a new version of the flight-specific software including the new I-Load values. This so-called "complementary FSW load," or Comp Load, was then thoroughly tested in the SPF and Shuttle Avionics Integration Laboratory (SAIL) prior to flight with these late changes. Examples of such late changes include TAL/ATO abort gap closure efforts, launch slips into the new calendar year that affect timedependent ascent guidance and navigation parameters, changes in abort landing site runway designations and navigation data, late breaking abort analysis affecting flight dynamics performance, unplanned payload weight growth or late significant deviations from control masses, late ET disposal footprint margin issues, late glide RTLS loads issues and "what-if" assessments to offload secondary payloads due to readiness issues such as offloading the AMS payload from the STS-91 mission (imposing a reduction in approximately $7000 \mathrm{lb}$ of payload).

AFD instituted an abbreviated design cycle, beginning only 30 days prior to launch and lasting only two weeks, to redesign the new uplinkable I-Loads. The final two weeks were reserved to allow for independent flight readiness verification by the systems integration organization and to allow for program systems integration technical reviews in support of the Certification of Flight Readiness (CoFR) process. This changed the paradigm such that changes now could be monitored continuously during the flight production timeline for applicability to this late design and verification cycle when the design was thoroughly evaluated, documented and statused for certification of flight readiness reporting. This not only saved resources, but significantly reduced the need to update ascent/entry guidance and sequencing I-Loads via lengthy I-Load patch reconfiguration, patch verification and testing processes in the SPF and the SAIL. This late update process in conjunction with the expanded capability to update key ascent GNC parameters via uplink was clearly beneficial to the ISS assembly missions, and was made available just at the right time when the frequency of unplanned ascent GNC I-Load patches was reaching a peak in 2001. The mission planning teams were able to utilize the full complement of such late update capabilities in support of the last 10 years of Space Shuttle missions.

\section{Summary / Key Takeaways}

The SSP has matured in reliability and cost of operations due to evolutionary improvements of the mission planning process that allowed the trajectory design to be performed as close to launch as possible, ideally after all critical mission attributes have been frozen.

- One key enabler for performing the design late is to decouple the mission specific trajectory design from crew and flight controller training.

- A second key enabler is to have a short-duration design process.

- A third key enabler is the capability to update the trajectory-related I-Loads close to launch, via uplink.

7

American Institute of Aeronautics and Astronautics

Placeholder for Copyright statement. 


\section{Implementing change management processes}

Because the success of a program is rooted in its ability to control its processes, evolve and grow to reduce cost and improve reliability/operability, the implementation of change management processes is critical. The data that AFD was responsible for was dependant on numerous information sources from multiple organizations throughout the SSP. For example, AFD trajectory simulation tools needed to model hardware systems owned by the Orbiter, ET, and Solid Rocket Booster (SRB) elements, AFD data products needed to properly reflect ET, OMS and Reaction Control System (RCS) propellant loading information that originated at Kennedy Space Center (KSC) Ground Operations, AFD I-Loads needed to conform to the constraints dictated by the Systems Engineering and Integration organization, and the processes established by the FSW organization. As a result, a change in nearly any corner of the SSP could ripple into AFD and create an impact to software tools, design processes, or personnel training. During these years, it was common for the ascent/entry flight design team to actively support, monitor and integrate at over 90 technical, planning and control board meetings with most meeting weekly. These meetings covered mission planning, flight operations, flight software, Orbiter specific, systems integration and program technical review and control boards, among others. It was imperative that AFD develop good systems engineering habits and change management processes in order to stay effective. Another consideration in support of a human spaceflight system was the sheer size of the flight design mission planning process that included hundreds of software tools, thousands of engineering and software documents and required the generation of thousands of analyses and mission products over the years. To maintain safety in such a complex mission planning environment, the application of proper mission design, constraint definition, trajectory control limits, and operational procedures is essential. This was the case for Projects Mercury, Gemini and Apollo ${ }^{1}$. The change management that accompanies these efforts is equally crucial.

\section{A. Examples of changes}

Changes that impacted AFD through the life of the SSP are too numerous to list, however a few examples can be used to illustrate the point. Some changes originated at the SSP level, including hardware changes like ET modifications, which drove AFD analysis of rupture altitudes and debris disposal zones. Another consistent area of such change was ascent aborts. Each space shuttle mission was designed to ensure that a certified abort could be performed at any time during the ascent flight phase. Over time, the abort options available to the crew on a particular mission evolved. For instance, the Transoceanic Abort Landing (TAL) abort mode was introduced early in the SSP to eliminate the need for an overlap between the RTLS and ATO abort modes. TAL landing sites were originally optimized for 28.5 degree inclination missions, and included such runways as Ben Guerir in Morocco, Moron in Spain, and Banjul in Gambia. Later, TAL landing sites were optimized by the SSP for 51.6 degree inclination missions headed to the ISS, so Istres, France was added. Introducing Istres as a new TAL landing site required not only new engineering analyses to design appropriate I-Loads and trajectories, but updates to software tools and procedures.

Other changes originated from within the mission operations community. One such change was the introduction of the option to intentionally delay the abort to a TAL site. For a typical TAL abort, the vehicle would begin steering toward its TAL runway shortly after the abort was declared. For missions to the ISS, this meant steering away from the U.S. East Coast. However if there were to be a second failure of an SSME shortly after TAL was declared, the vehicle might need to steer back toward the East coast in an attempt to complete a contingency landing. The idea of a delayed TAL was to not declare TAL immediately upon the recognition of the need to abort; rather, the situation would be monitored, during which time the vehicle continued to stay close to the east coast. If no other failures occurred, a TAL would be declared in time to achieve a successful landing. If a second failure did occur, the capability to land somewhere on the east coast had been improved. TAL delay was a fairly straightforward idea that arose from the mission operations community and was implemented fairly rapidly via Flight Rule update. However, AFD incurred a significant analysis cost to first verify the idea could work as planned, to update mission planning design systems and processes and then to generate trajectories and associated data to feed the operations team for use during training simulations and real-time support. The wide variety of scenarios involved drove the analysis size and complexity: launches at various times in the launch window (which affects the proximity of the groundtrack to the east coast, and therefore the landing capability), failures at different mission elapsed times (which drive abort performance and capability), variability in the duration to delay the TAL abort action, landings to three different potential TAL sites, and landings to multiple different east coast contingency sites.

8

American Institute of Aeronautics and Astronautics Placeholder for Copyright statement. 
Finally, still more changes originated from within AFD. For example, the process improvement efforts described above (ISS Standardization and JITFD) resulted in numerous impacts to procedures, tools, and training materials.

\section{B. Examples of mitigation strategies}

AFD developed specific mitigation strategies to accommodate changes. Three that will be discussed here are process documentation, a change evaluation system, and an anomaly reporting system.

Process documentation included procedures, checklists, and training materials. This information served as the foundation of knowledge about the way things worked in AFD. The backbone of the documentation was the Flight Design Handbook, which was a multi-volume set of procedures governing mission design processes. The collective documentation served an especially important role due to the long duration of the SSP; over the SSP's 30 years personnel tended to turn over and corporate knowledge could be lost if it was not written down. A solid documentation base was a key to understanding process baselines, such that impacts due to a particular change could be properly understood.

A second key mitigation strategy was a formal change evaluation system. This system included a Design Impact Form (DIF) and a Design Impact Database (DID). Figures 4 and 5 shows representative entries made into the DID.

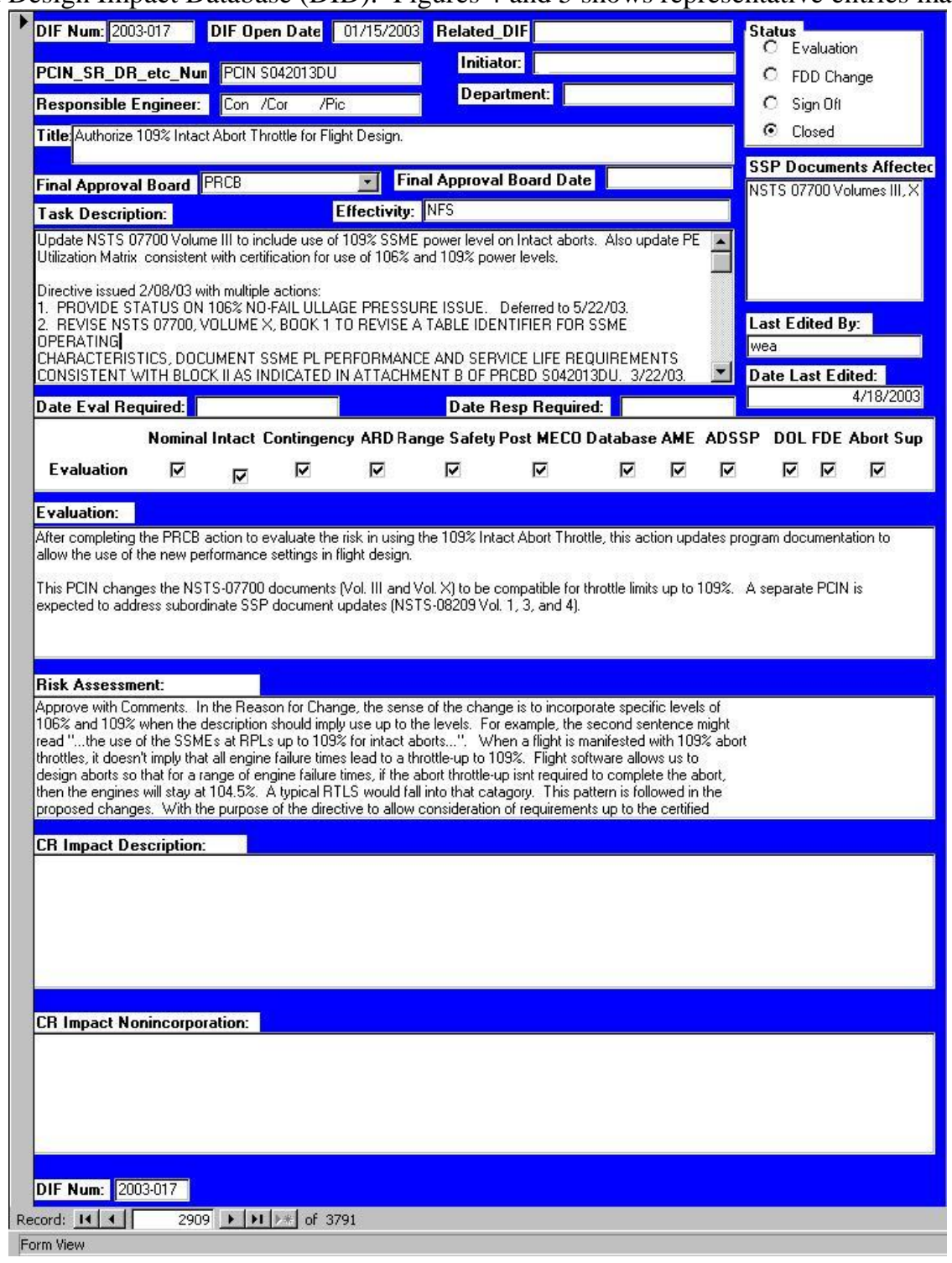

Figure 4: Representative example of DIF entries in the DID (Page 1).

9

American Institute of Aeronautics and Astronautics

Placeholder for Copyright statement. 


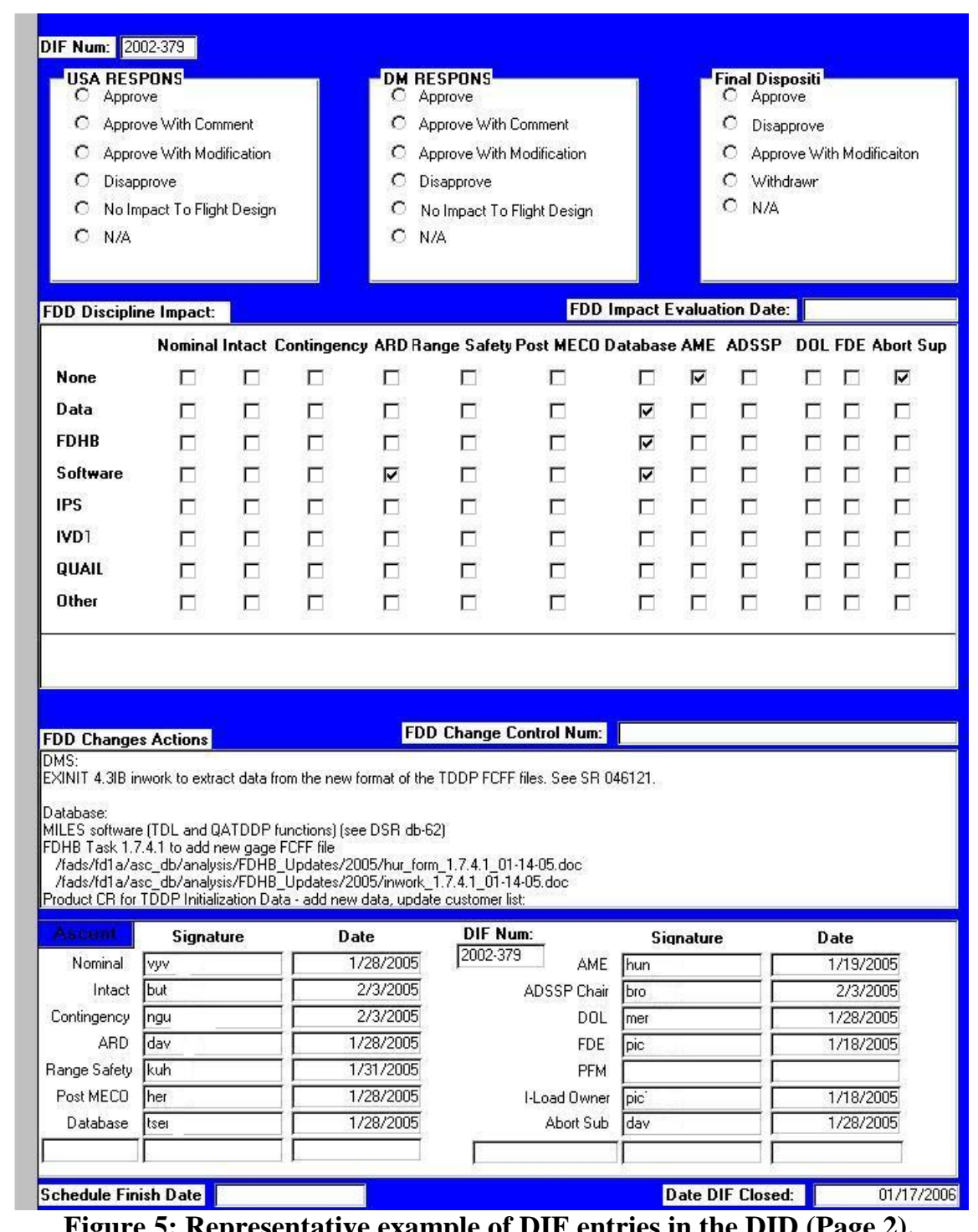

When a new change was identified, a DIF would be filled out to capture the change. The DIF was then circulated to the AFD lead engineers, who would perform an impact assessment. The form included a checklist of memoryjoggers to help the lead engineers evaluate all aspects of the change (procedures, software, training materials, etc.). It was important to consider the full effect of the change not just within the changed system, but to adjacent systems and operations. The impacts were collected and entered into the DID.

The system was closed-loop in the sense that impacts led to action items that were formally tracked to closure. In addition, the entire team of lead engineers had insight into the impacts, which significantly increased the likelihood of identifying second-order ripple effects (e.g., "if the Aborts discipline changes their product, software or procedures, the Range Safety discipline will need to change theirs as well", or "if the engine or model characteristics are changed, then one may need to redesign hardware-dependent flight software guidance and sequencing parameters"). To give the reader a feel for the need for this type of system, the DID contains thousands of records of changes that were evaluated and implemented by flight design disciplines from 1994 to 2011. This same system was also used to formally respond to program change instrument evaluations and document approval, comments with changes, and disapprovals with rationale for later consideration by SSP program technical panels and control boards. 
A formal anomaly reporting system was also a critical mitigation strategy. Anomaly Reports (ARs) were written to document when things did not go as planned. These ranged from serious issues, of which there were thankfully only a handful, to smaller items, which represented the majority. It was simple to open an AR - the only information required was a description of what went wrong and basic tracking information.

Each AR was taken seriously, regardless of the severity of the problem that resulted. Personnel were trained not to stop when symptoms had been treated, but rather to identify and correct root causes. This philosophy was reinforced by documenting not just the immediate correction to the problem, but long-term corrective action which would ensure the problem did not happen again. The AR was not closed until after both the immediate and the long-term actions had been completed. Over the years the AR system documented hundreds of problems across all flight design disciplines, and provided valuable insight into AFD and other processes. Because problems were identified and fixed when they were small, it was very rare for a large problem to develop. Figure 6 below shows a blank AR form.

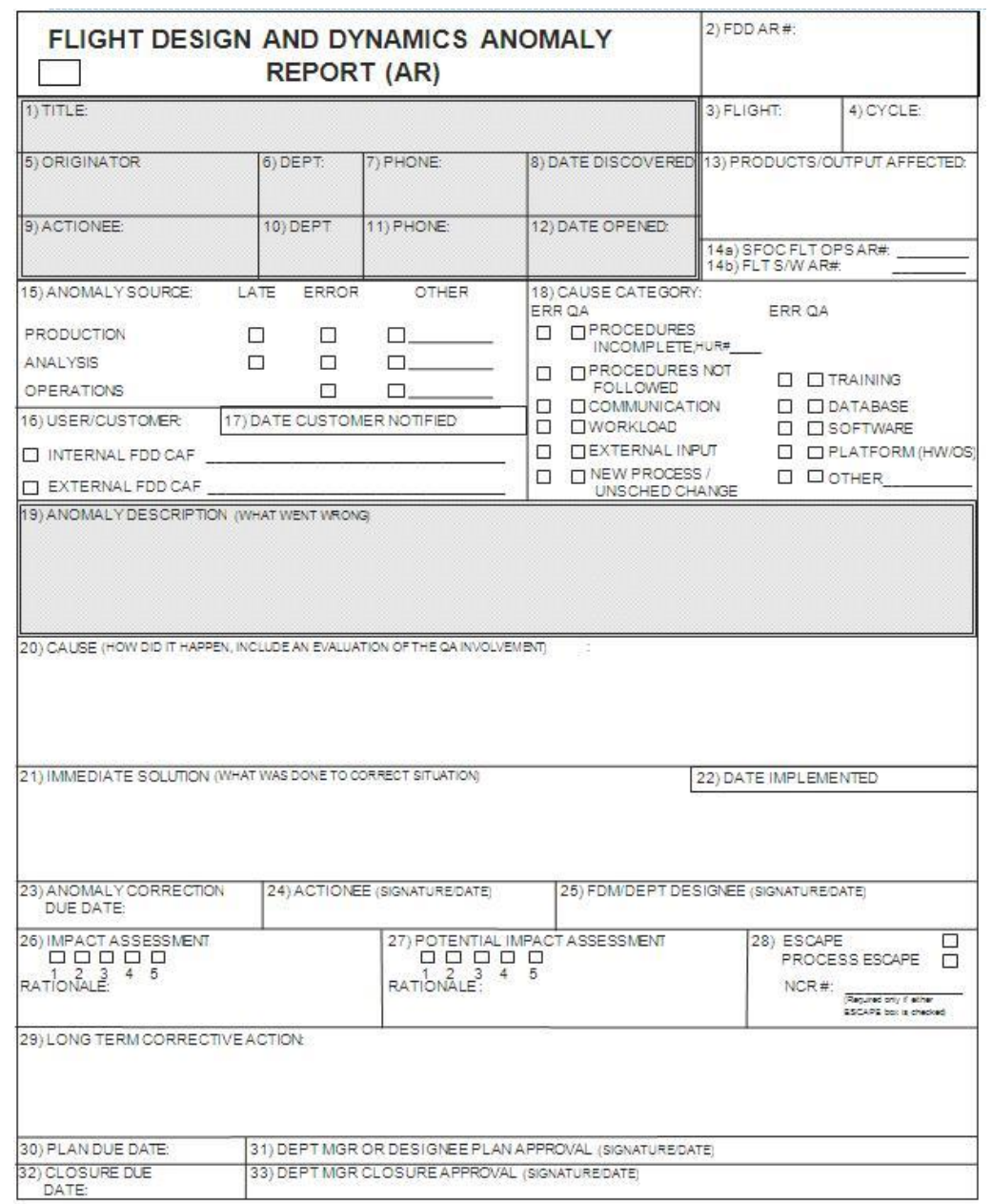

Figure 6: Blank Anomaly Reporting form

\section{Summary / Key Takeaways}

Expect change, especially in dynamic areas of human spaceflight. Build processes to accommodate such change.

- Process documentation serves as the foundation for the organization's knowledge base.

- A formal system to evaluate changes can help identify and ensure timely completion of first- and secondorder impacts.

- A formal anomaly reporting system can help ensure root causes are addressed so that problems are not repeated. 


\section{Maintaining quality in times of cost reductions and content increases}

Many organizations have been faced with "doing more with less" and AFD is no exception. For AFD, it was essential to ensure that quality did not suffer during an environment of cost reductions and content additions. Rather than focus on specific headcount numbers, this section will provide an overview of a general management philosophy and some specific strategies that led to organizational success.

Local management in AFD successfully pushed decision making authority deep into the organization. In 1994 AFD switched from a hierarchical structure, where the lead engineers in each technical discipline were members of management, to a matrix structure, where the lead engineers ran each technical discipline as a self-directed work team and a separate set of (fewer) first-line managers oversaw the entire organization. This matrix structure was extended to technical disciplines as well, as an individual often had roles in multiple disciplines. In addition, each discipline was responsible for all components of the related work, including analysis, mission specific design, and real-time support. This was in contrast to other SSP organizations that focused on one (or perhaps two) of those three components. To encourage cross-discipline coordination, key formal engineering and software technical coordination meetings were established that included lead engineers and subject matter experts.

Since the management team had responsibility for the overall organization, not a single slice of it, organizational issues such as "kingdom building" and "turf wars" were avoided. The management team set department goals, established priority lists which reinforced the goals, and deployed resources accordingly in coordination with the technical discipline lead engineers. As AFD's work changed, the management team adapted. For example, they recognized an overlap in skills between the group responsible for design of the pre-mission nominal trajectory (among other items) and the group responsible for design of the launch day nominal trajectory (among other items). The technical groups were merged to eliminate the overlap, enabling a real reduction in AFD's headcount.

While the organizational structure helped push decision-making down into the organization, other processes helped ensure quality. Examples include process documentation such as the Flight Design Handbook, the DIF/DID system, and the AR system, all mentioned above. Another example is the rigorous change control processes used to provide configuration management of procedures, software tools and associated data. In addition, AFD relied on technical training programs not just for junior engineers but for experienced engineers as well, to ensure all personnel were constantly developing new skills.

These strategies allowed AFD to expand its responsibilities over time, while maintaining the high quality absolutely essential to a human spaceflight program. For example, in 1996, a new contract called the Space Flight Operations Contract (SFOC) was introduced. Under SFOC, flight design, including AFD, became a contractor-accountable function with reduced government involvement required. In 1998, the Space Shuttle Program Office transitioned coownership of the requirements management of Space Shuttle FSW guidance, navigation, and cockpit display principal functions to AFD. Also in 1998, the government transitioned co-ownership of I-Load management to AFD. In each case, the complementary co-owners were assigned from the systems integrationorganization. This synergy between operations and the systems integration organization was healthy and essential to ensure that design changes were informed with operations expertise and impacts. The addition of flight software principal function requirements management and I-Load management and ownership significantly expanded AFD's responsibilities within the SSP, and introduced the new positions of AFD Principal Function Manager (PFM) and AFD I-Load Owner (ILO). Such heightened ownership and responsibility under the SFOC also led to AFD taking the SSP lead or providing key contributions in authoring and implementing some of the marquee guidance and navigation changes in the Shuttle program. These changes included the development of onboard GNC uplink capability (OI26, OI-28, OI-29), GPS (OI-27), updates to ascent guidance algorithms to allow variable SSME throttle limits as a function of abort mode to provide the SSP the flexibility to properly manage ascent abort risk, the onboard calculation of the navigation rotation, nutation, and precession (RNP) matrix (OI-29) to accommodate launch delays, and key updates to the crew trajectory reference displays for increased situational awareness during ascent/entry (OI-32, OI-33). Adding such visible and important roles as PFM and ILO to AFD also improved the overall skill mix, by retaining high-caliber personnel to perform the roles. This had a positive effect on quality as well.

12

American Institute of Aeronautics and Astronautics Placeholder for Copyright statement. 
US human spaceflight programs have had a continuous focus on quality and safety, starting with the Mercury Program and continuing through today (see Figures 2 and 7). This focus clearly left its mark on the AFD organization.
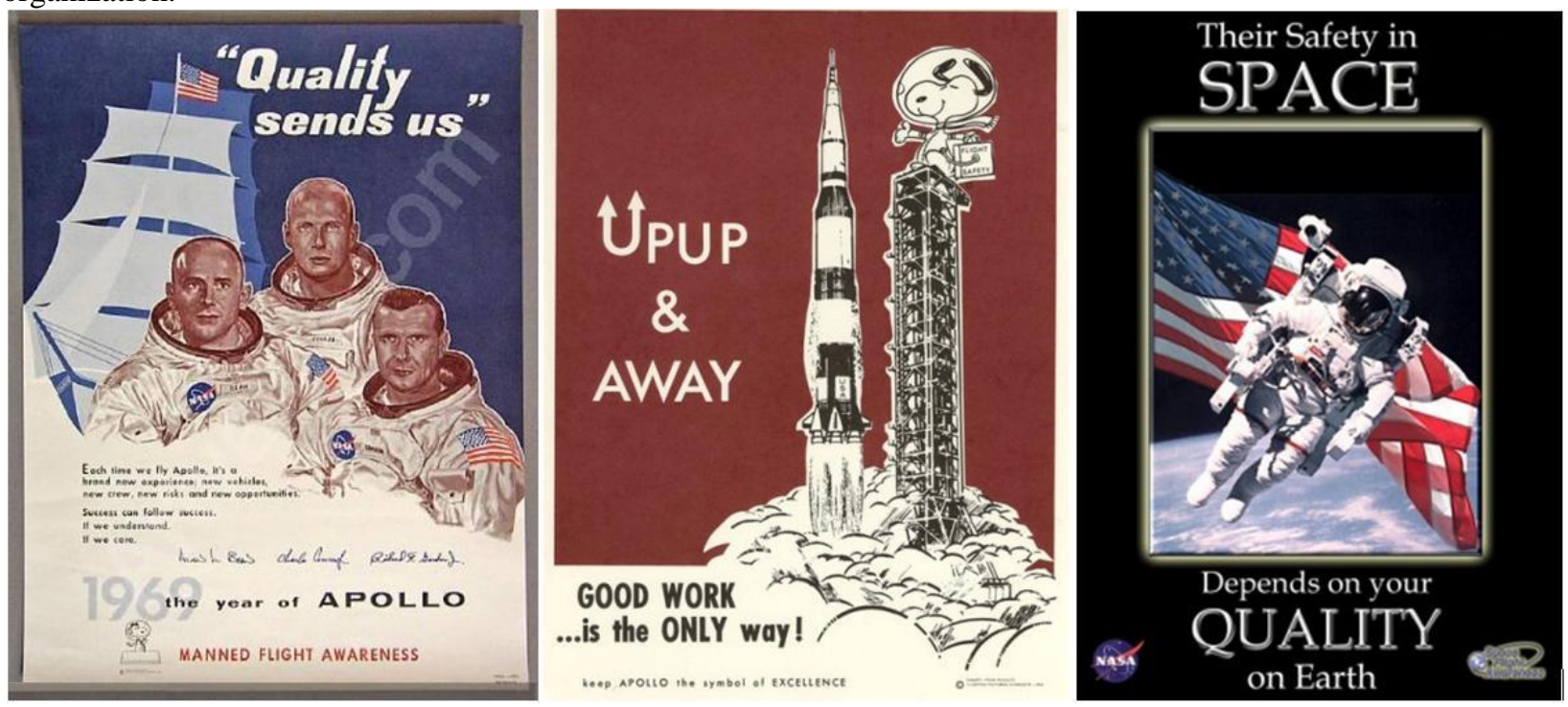

Figure 7: Motivational NASA Posters Addressing Quality -Apollo and Space Shuttle Programs

\section{Summary / Key Takeaways}

Considering the success in the AFD implementation of quality processes, the reliability is in the pudding as the success of this mission planning system can now be measured over literally hundreds of mission planning cycles. Key takeaways are:

Management philosophy will impact the organization's chance of success.

- For AFD, a matrix organization model was a key to successfully "doing more with less."

Organizational processes help ensure quality.

- For AFD, these included change control processes and technical training programs.

Expanding an organization's responsibilities can help ensure quality.

- For AFD, the transition to FSW requirements management, trajectory design and reconfiguration responsibilities via the PFM and ILO roles had a positive impact on quality.

\section{Additional Operations Experience \& Lessons Learned}

AFD experience yields multiple additional lessons learned regarding ascent flight design and operations that are only briefly summarized below. Key categories of lessons include FSW requirements, trajectory design and verification, and I-Load reconfiguration and uplinks.

\section{A. FSW Requirements}

Key takeaways from the AFD experience regarding flight software requirements management include:

- As mentioned above, AFD PFMs and ILOs shared ownership of guidance and display functions with another organization. Dual ownership allowed AFD to provide the operations experience to inform the design baseline, a perspective that would have otherwise been missing; similar ownership arrangements should be considered for future programs.

- When designing FSW, carefully consider costs/benefits of providing automation capabilities on-board, versus relying on mission-to-mission I-Load reconfiguration. It may be possible to reduce sustaining engineering costs during the operations phase by pursuing closed-loop guidance functionality, especially for dynamic flight phases or events. However, such automation will come at a price during the development phase.

- Ensure that FSW requirements have an ability to completely inhibit new functionality, to allow staged implementation of updates between major FSW upgrades. There were cases where SSP FSW updates were 
left inhibited (i.e., not turned on) due to programmatic decisions, and the option of leaving the update "off" avoided significant rework that would have been required to back out the change.

- Strive for consistency between design and verification requirements and documentation, at all levels of the program. For SSP, AFD interfaced with multiple verification systems on different platforms, which at times led to different constraints with multiple purposes .

\section{B. Trajectory Design and Verification}

Key takeaways from the AFD experience regarding trajectory design and verification include:

- Avoid the temptation to limit the verification trajectory case matrix to representative trajectory cases based on engineering judgment. Rather, as sometimes more is better, favor a comprehensive verification approach for trajectory types associated with dynamic flight phases and events, especially when computing power allows full trajectory scans and the generation of automated verification constraint reports. Such approaches can identify verification and certification "holes" early in the design and operation phases.

- On the other hand, avoid the temptation to implement over-automated design and verification processes ("single pushbutton" methods). Rather, design tools with key checkpoints to allow for intervention to iterate or resolve issues.

- Implement trajectory and I-Load constraint checks as far upstream as possible and in as few design, verification, reconfiguration and command systems as beneficial to avoid unnecessary overhead and oversights.

- Ensure that I-Load constraint checks represent and are tested for the full operational envelope.

- Document performance studies and analyses for later reference or re-use, such as for abort improvement, abort gap closure and no-fail performance improvement efforts. These topics seemed to resurface again and again; a full cognizance of prior work, including ground rules and assumptions, went a long way in ensuring AFD did not have to "reinvent the wheel" each time.

- Implement a mission change tracking system for all program elements to ensure a common generic and mission-specific requirements baseline. For SSP, a system existed to capture the proper version of each requirements document, and any program-approved overrides or deviations. This went a long way in ensuring commonality between numerous organizations for design, verification, reconfiguration, training, and flight.

- Ensure that trajectory design and verification organizations have access to simulations that include embedded actual flight software to allow for analysis of intricate software initialization, sequencing and other performance issues.

- Require that design and verification mission planning processes avoid the use of hardcoded system limits to maintain flexibility and avoid costly upgrades..

\section{I-Load Reconfiguration and Uplinks}

Key takeaways from the AFD experience regarding I-Load reconfiguration and uplinks include:

- Ensure data compatibility between onboard and ground systems.

- Implement a smart selection criteria process to reconfigure large datasets that are static or can be mapped against repeatable mission characteristics.

- Implement rigorous transfer QA requirements to ensure not only that the data is correct, but that the data was successfully transferred for testing, training or flight and is applicable to the mission at hand.

- Avoid the use of derived I-Loads (i.e., prior to uplink to the FSW, one I-Load's value is calculated based on another I-Load's value). SSP's use of derived I-Loads initially reduced the onboard code count yet increased the verification costs via additional I-Load audits and patch verification efforts.

- Establish a clear definition of required I-Load uplink content early in the program, to avoid later implementation costs. Preferably, allow the uplink of all reconfigurable parameters while allowing the administrative/management process to constrain what parameters may be updated.

- Retain key reconfigured or uplinked data on major operational FSW transitions, such as ascent to entry. For SSP, some uplinks (e.g., landing site table I-Loads) were lost on this transition thus increasing operations cost. 


\section{Conclusion}

The AFD team has directly contributed to the success of the SSP via innovation and sustained reliability through incremental evolution. Strategic initiatives, such as moving the work as late as possible and reducing cycle times, helped provide the SSP with the flexibility necessary to take advantage of the Space Shuttle's remarkable capabilities. Change management processes ensured that AFD procedures, software tools, and training materials kept pace with the frequency and complexity of updates originating at all levels of the SSP. And right through the end of more than 30 years of Space Shuttle ascent operations marked by the successful launch of STS-135/Atlantis on July 8, 2011, despite cost reductions and work content additions, AFD maintained the exceptional quality required of a human spaceflight program. In these ways, AFD was creative in designing and implementing strategies to ensure their success. In all cases, these successes can be directly attributed to the same safety culture that has been honed throughout all US human spaceflight programs. The challenges encountered, and the mitigation strategies implemented, point to lessons learned that may be applicable to similar work on future programs.

\section{Nomenclature}

\begin{tabular}{|c|c|}
\hline AFD & $=$ Ascent Flight Design \\
\hline AR & $=$ Anomaly Report \\
\hline ATO & $=$ Abort To Orbit \\
\hline BFS & $=$ Backup Flight System \\
\hline CGx & $=$ Longitudinal center of gravity \\
\hline DID & $=$ Design Impact Database \\
\hline DIF & $=$ Design Impact Form \\
\hline ET & $=$ External Tank \\
\hline FDRD & $=$ Flight Definition and Requirements Directive \\
\hline FOP & $=$ Flight Operations Panel \\
\hline FSW & $=$ Flight Software \\
\hline GNC & $=$ Guidance, Navigation, Control \\
\hline GPS & $=$ Global Positioning System \\
\hline I-Load & $=$ Initialization Load \\
\hline ILO & $=\mathrm{I}$-Load Owner \\
\hline ISS & $=$ International Space Station \\
\hline JITFD & $=$ Just In Time Flight Design \\
\hline KSC & $=$ Kennedy Space Center \\
\hline L- & $=$ Launch minus \\
\hline MCC & $=$ Mission Control Center \\
\hline MECO & $=$ Main Engine Cut Off \\
\hline OI & $=$ Operational Increment \\
\hline OMS & $=$ Orbital Maneuvering System \\
\hline PASS & $=$ Primary Avionics Software System \\
\hline PFM & $=$ Principal Function Manager \\
\hline QA & $=$ Quality Assurance \\
\hline RNP & $=$ Rotation, Nutation and Precession \\
\hline RTLS & $=$ Return to Launch Site \\
\hline SAIL & $=$ Shuttle Avionics Integration Laboratory \\
\hline SFOC & $=$ Space Flight Operations Contract \\
\hline SMS & $=$ Shuttle Mission Simulator \\
\hline SPF & $=$ Software Production Facility \\
\hline SRB & $=$ Solid Rocket Booster \\
\hline SSME & $=$ Space Shuttle Main Engine \\
\hline SSP & $=$ Space Shuttle Program \\
\hline STS & $=$ Space Transportation System \\
\hline TAL & $=$ Transoceanic Abort Landing \\
\hline TDDP & $=$ Trajectory Design Data Package \\
\hline
\end{tabular}

15

American Institute of Aeronautics and Astronautics Placeholder for Copyright statement. 


\section{References}

${ }^{1}$ C.R. Huss, C.R. Hicks, and C.C. Allen, "Mission Design for Flight Safety", NASA MSC Internal Note No.67-FM175, November 17, 1967.

${ }^{2}$ Sol Levine, "Manrating the Gemini Launch Vehicle", AIAA Paper No. 64-274, June 1964. 


\title{
Space Shuttle Ascent Flight Design Process: Evolution and Lessons Learned
}

\author{
Bret Picka/United Space Alliance \\ Christopher Glenn/NASA Johnson Space Center \\ AIAA Space 2011 Conference \\ September 26-29, 2011 \\ Long Beach, California
}

* United Space Alliance

The Space Operations Company ${ }^{\circledR}$ 


\section{Agenda}

- Background / Introduction

- Moving the work as late as possible

- Change management processes

- Maintaining quality

- Ops experience \& lessons learned

- Conclusion

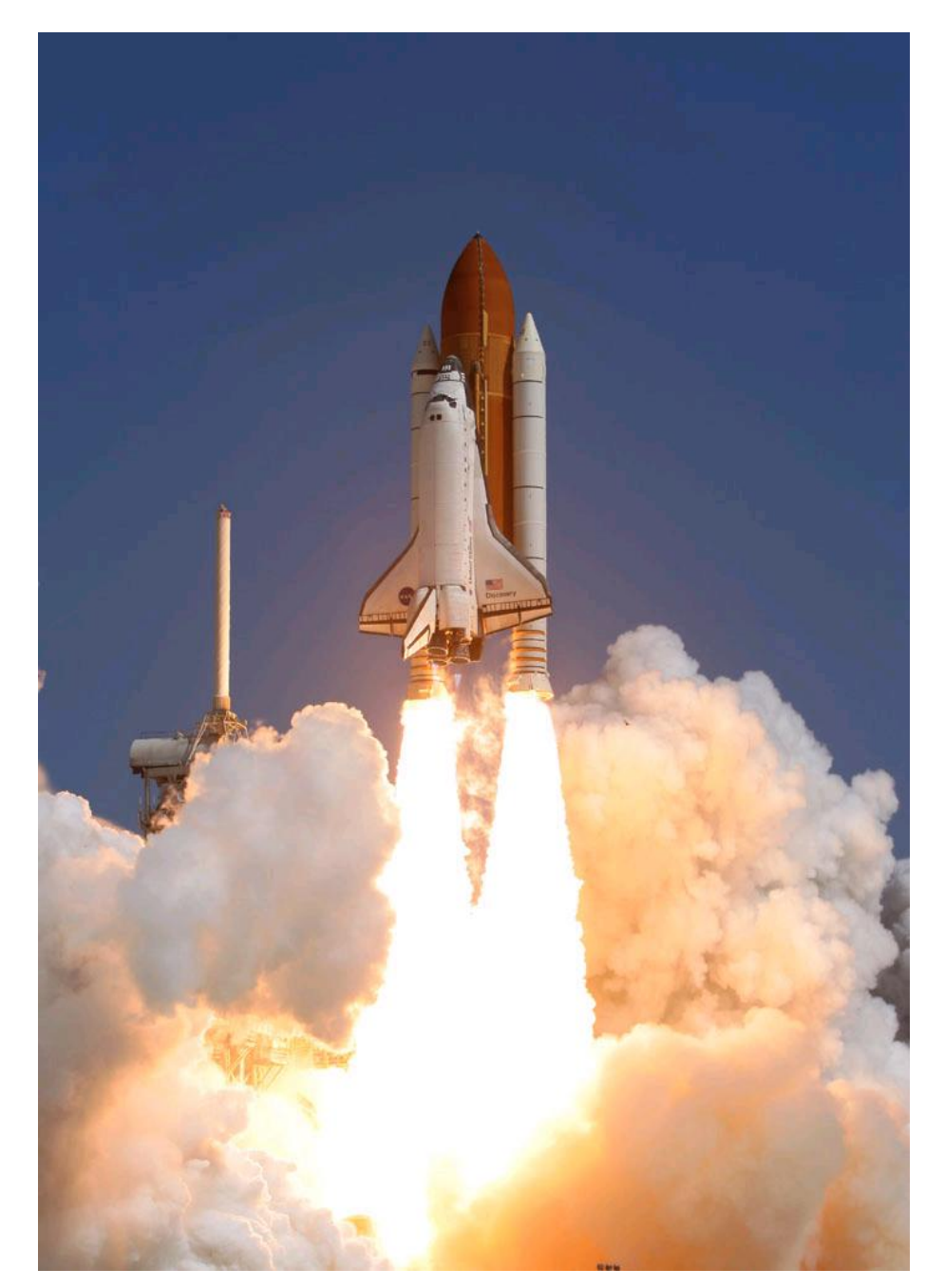




\section{Background / Introduction}

- The Ascent Flight Design (AFD) team defines a launch to orbit operational trajectory profile

- Satisfies programmatic mission objectives

- Defines the ground and onboard reconfiguration requirements

- Design, verification and reconfiguration process ensures that all mission scenarios are enveloped within integrated vehicle and spacecraft certification constraints and criteria

- Mission scenarios include nominal ascent and both uphill and ground-toground aborts

- Intact aborts are protected to a robust level similar to the no-fail, and ensure the safe return of the flight crew and the Orbiter for reuse

- Ascent trajectory design and mission planning has evolved

- Improve program flexibility, reduce cost, while maintaining quality

- An ongoing process throughout 135 missions 


\section{Background / Introduction}

- Products are used in crew and flight controller training, avionics flight software verification, and operations

- These products provide the flight crew, flight control team, and various support facilities the insight and situational awareness necessary for

- Trajectory and flight dynamics

- Performance and event sequences

- Abort mode boundaries and moding

- Flight performance and impact predictions for launch vehicle stages (Range Safety)

- Flight software performance

- Tracking systems

- Launch collision avoidance

- Day of launch performance, targeting and onboard GNC updates 


\section{Challenge: Program Flexibility}

- Space Shuttle was an incredibly capable vehicle

- Accommodated a wide variety of missions

- No-fail and abort designs had to address significant variations in

- Orbital inclination and altitude

- Propellant loads

- Mass properties

- Launch environment

- Program processes

- Initially evolved out of a development program

- Lacked flexibility in handling dynamic manifests, high flight rates, changes to baseline mission requirements and hardware mods

- Were a significant challenge in the presence of tight budgets, the need to upgrade aging vehicles/facilities and need to perform safety modifications 


\section{Challenge: Program Flexibility}

- Solution: Move the work as late as possible

(1) Flight Operations Reinvention and ISS Standardization efforts

- Removed training support products from the critical path

- Used standardized trajectories/products for crew/controller training

- Moved ascent/entry designs closer to launch where manifest stable

- Reduced the probability of late changes with reassessment/rework

\begin{tabular}{|l|l|l|}
\hline Milestone & Base Schedule & $\begin{array}{l}\text { ISS Standardization } \\
\text { Schedule }\end{array}$ \\
\hline Trajectory Design Initialization Data & L-303 days & L-198 d \\
\hline Design Start (FOP meeting) & L-288 d & L-178 d \\
\hline Design Submit (I-Load) & L-233 d & L-128 d \\
\hline Design Approval (I-Load) & L-210 d & L-105 d \\
\hline SMS/MCC Load releases & L-127 d & L-29 d \\
\hline Ready-for-Training & L-126 d & L-28d \\
\hline
\end{tabular}




\section{Challenge: Program Flexibility}

- Solution: Move the work as late as possible

(2) Just In Time Flight Design

- Follow-on and worked in conjunction with ISS Standardization

- Created more efficient flight design process via the reduction in internal hand-offs, redundant QA steps and duplication of efforts that crept into the system over the first two decades

- Added a smart design initialization process to establish a high quality baseline from which the design could be matured

- Took good advantage of client server parallel processing capabilities to process a high number of iterative trajectory performance trades and optimization tasks

- Design cycle times had been reduced from seven to five weeks

- Allowed for much quicker technical assessments and fast-track analysis
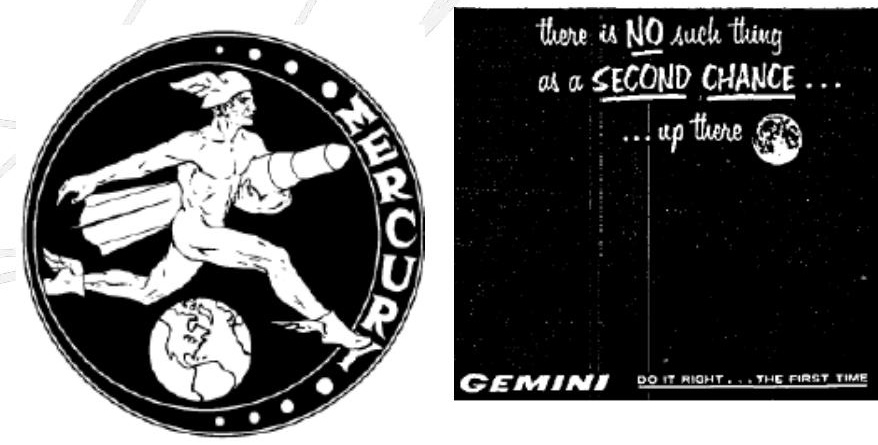

DO IT RIGHT . . . THE FIRST TIME 


\section{Challenge: Program Flexibility}

- Solution: Move the work as late as possible

(3) Expanded GNC Initialization loads (I-Load) parameter uplink

- I-Loads are used to overwrite values of critical GNC parameters resident in the flight software with a new value

- I-Load uplinks use dedicated ground and onboard flight software to update I-Loads on day-of-launch

- For much of the SSP, ascent/abort related uplinks were limited

- First stage boost pitch/yaw profile, throttle commands, winds

- Orbital plane steering target, and insertion burn targets

- Later flight software upgrades included additional uplink capability

- No-fail and abort powered flight targets, and key GNC parameters that are sensitive to vehicle mass and performance such as Orbiter propellant dump durations and capability boundary velocity switches

- STS-110 was the first flight to incorporate a full complement of uplink upgrades (April 8, 2002 launch) 


\section{Challenge: Program Flexibility}

- Solution: Move the work as late as possible

(4) Late Design Cycle

- Prior to the expanded GNC I-Load parameter uplink capabilities

- Each significant mission configuration change often involved detailed reassessments

- If an issue was found, then often GNC I-Load parameters needed updates and an "I-Load Patch" to the flight software was necessary

- These patches were intrusive, costly and time-consuming due to the nature of patch parameter processing via the software production facility, the verification and approval process, the patch build and testing efforts

- AFD instituted abbreviated design cycle beginning 30 days before launch

- Two week effort to redesign/re-verify the trajectory design profiles

- Final two weeks were reserved for independent flight readiness verification by the systems integration organization and to allow for program reviews in support of Certification of Flight Readiness (CoFR)

- Late changes were now assessed against this uplink capability

- Significantly reduced I-Load patch and verification efforts

- Very beneficial to the ISS assembly missions 


\section{Challenge: Program Flexibility}

- Summary / Key Takeaways

- The SSP had matured in reliability and cost of operations due to evolutionary improvements of the mission planning process

- Trajectory design was performed as close to launch as possible, ideally after all critical mission attributes had been frozen

- Key enablers for late design efforts were to

- decouple the mission specific trajectory design from crew and flight controller training

- Implement a short duration trajectory design and verification process

- Update the trajectory and mission configuration sensitive GNC ILoad parameters close to launch via prelaunch uplink 


\section{Challenge: Managing Change}

- Change management processes are critical

- Success of a program is rooted in its ability to control its processes, evolve and grow to reduce cost and improve reliability and operability

- AFD was dependent on multiple requirements and data sources from multiple organizations across the country

- A change in any corner of the program could create an impact to planning and real-time software tools/simulators, design processes, products or personnel training

- At peak activity, the group interacted with over 90 standing technical panels, control boards and technical interchange groups

- It was imperative that AFD develop good engineering habits and change management processes 


\section{Challenge: Managing Change}

- Another consideration was the size and complexity of mission planning systems and processes

- Hundreds of software tools, millions of source lines of code

- Thousands of engineering, operations and software documents

- Thousands of analyses and mission products

- To maintain safety, the application of proper mission design, constraint definition, trajectory control limits and operational procedures is essential

- No different than for Mercury, Gemini, Apollo, Skylab, ASTP 


\section{Challenge: Managing Change}

- Mitigation Strategies

- Process documentation

- Engineering and operational procedures, process checklists, and training materials

- Foundation of knowledge, and a solid documentation baseline that was key to understanding process baselines such that change impacts could be properly understood and implemented

- Such documents are critical especially in a 30-year program

- Change evaluation system

- Change impacts were evaluated via the use of a Design Impact Form (DIF) and Design Impact Database (DID)

- Allowed the change evaluation to reflect all process impacts, all stakeholders, mission impacts

- Also used for formal responses to program change instrument evaluations and concurrence/disapproval

- An Anomaly Reporting (AR) system to document immediate and long-term corrective actions 


\section{Challenge: Managing Change - Example Design Impact Form (subset)}

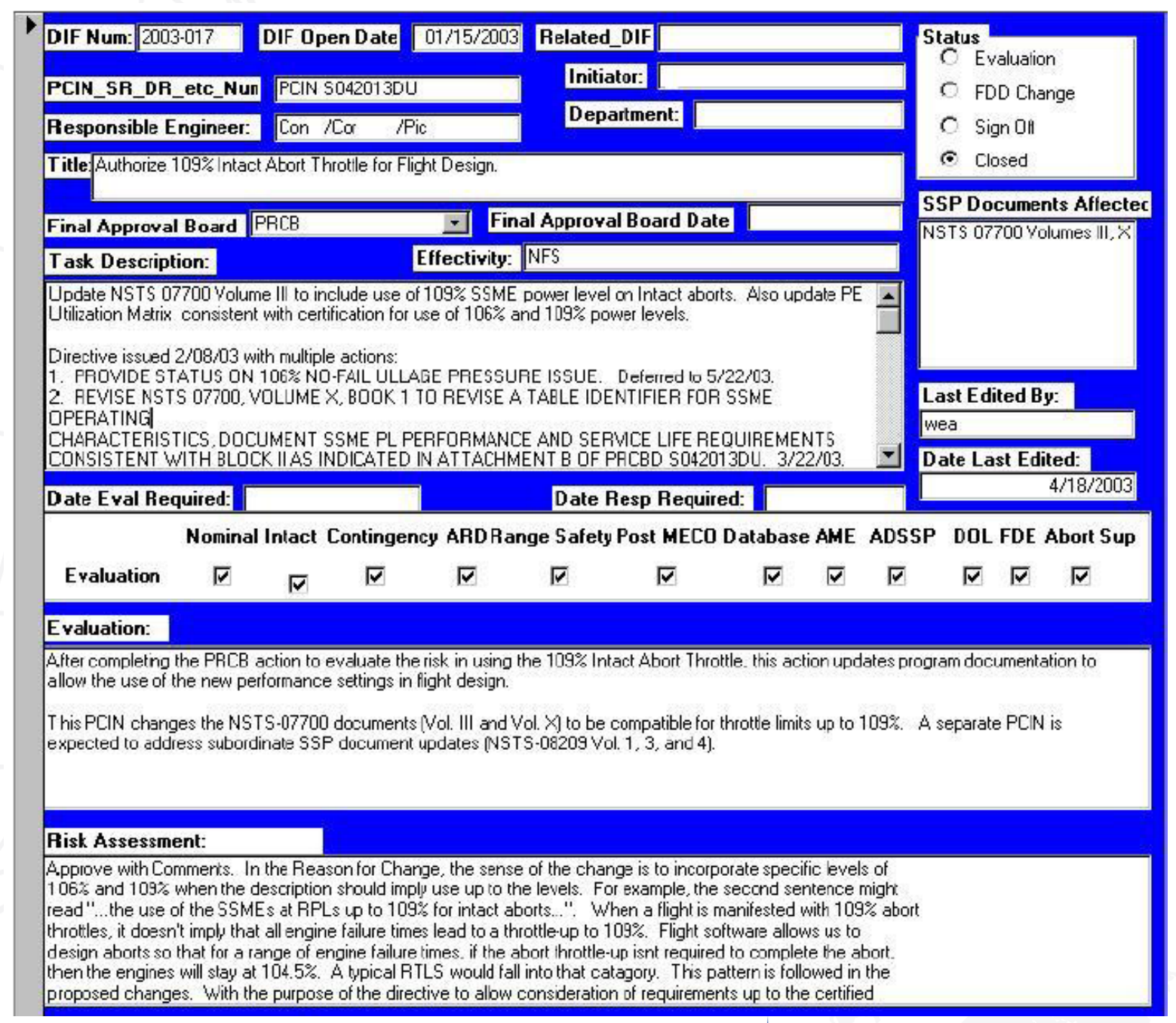




\section{Challenge: Managing Change}

- Summary / Key Takeaways

- Expect change, especially in dynamic areas of human spaceflight

- Build processes to accommodate such change

- Process documentation serves as the foundation for an organization's knowledge base

- A formal system to evaluate changes can help identify and ensure a timely completion of first and second order impacts

- A formal anomaly reporting system can ensure root causes are addressed so that problems are not repeated 


\section{Challenge: Maintaining quality}

- US human spaceflight programs have had a continuous focus on quality and safety

- Various processes enhanced quality

- Already mentioned: process documentation, DIF/DID system, and the AR system

- Rigorous change control processes to provide configuration management of procedures, SW tools and associated data

- Reliance on technical training programs for junior and experienced engineers to ensure development of new skills

- These strategies allowed AFD to expand responsibilities

- Reduced government involvement via contract allowed AFD to take ownership of key contractor accountable functions

- Program transitioned ownership of requirements management of Space Shuttle flight software and I-Load functions to AFD for ascent/entry/onorbit guidance, navigation and cockpit display

- AFD took the lead in authoring key GNC capabilities and was able to retain high-caliber personnel 


\section{Challenge: Maintaining quality}

- It was essential to ensure quality in an environment of cost reductions and content additions

- Decision making authority was pushed deep into the organization which improved quality and timeliness

- Old organization was vertically aligned with lead engineers as members of line management

- Evolved to lead engineers running technical disciplines as self-directed work teams; a small set of line managers oversaw the organization

- Eliminated kingdom building and turf wars

- Management team set goals, priority lists which reinforced goals, and deployed resources accordingly in coordination with lead engineers
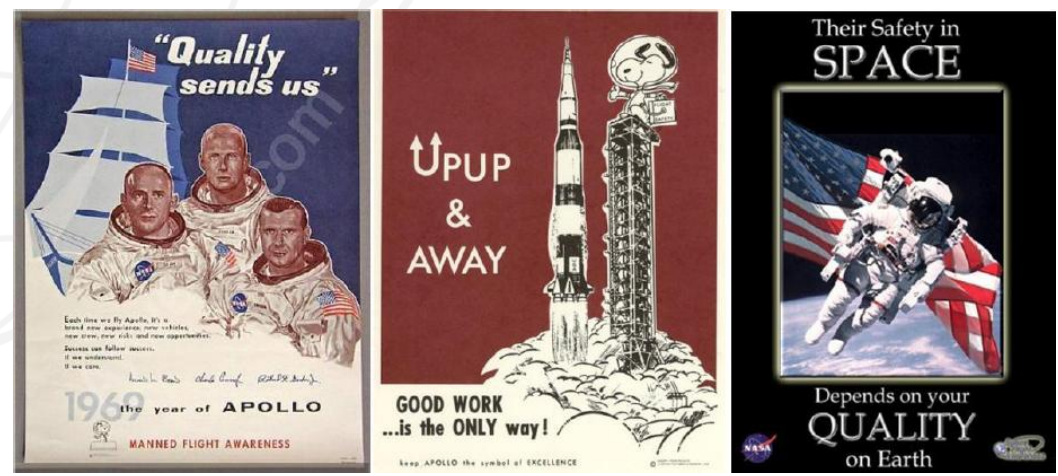


\section{Challenge: Maintaining quality}

- Summary / Key Takeaways

- AFD processes and mission planning systems were successful in maintaining a high level of quality and safety, measured over hundreds of mission planning cycles

- Management philosophy will impact an organization's chance of success, and a matrix organization model was key in doing more with less

- Organizational change control processes and technical training programs are key in ensuring quality

- Expanding an organization's responsibilities can help ensure quality such as requirements, design and reconfiguration responsibilities 


\section{Challenge: Additional Operations Experience \& Lessons Learned}

- Flight Software Requirements

- Consider dual ownership of requirements for GNC flight software and GNC I-Load parameter management between development and operations organizations

- Perform careful cost/benefit trades of providing automation capabilities onboard vs. relying on mission-to-mission I-Load configuration

- Ensure that flight software upgrades include an ability to fully inhibit all new functionality to

- allow staged implementation of updates between major software upgrades, and to

- avoid significant rework to back out a change

- Strive for consistency between design and verification requirements and documentation to avoid reqt's creep/cost 


\section{Challenge: Additional Operations Experience \& Lessons Learned}

- Trajectory Design and Verification

- Identify verification and certification "holes" early in the design and operations implementation phase

- Avoid the temptation to oversimplify trajectories and flight dynamics by prematurely picking a small subset of representative cases

- Avoid the use of over-automated design and verification processes/tools

- Design tools/processes with key checkpoints to allow for intervention to iterate or resolve issues

- Ensure that trajectory constraint checks represent and are tested for the full operational envelope

- Implement a mission change tracking system for all program elements

- Ensure a common generic and mission-specific requirements baseline

- Ensure commonality between numerous organizations for design, verification, reconfiguration, training and flight

- Use simulations that include embedded actual flight software

- Allows analysis of intricate software initialization, sequencing and performance issues 


\section{Challenge: Additional Operations Experience \& Lessons Learned}

- Initialization Load Reconfiguration and Uplinks

- Ensure data compatibility between onboard and ground systems

- Implement a smart selection criteria process to reconfigure large datasets that are static or that can be mapped against repeatable mission characteristics

- Implement rigorous transfer QA requirements to ensure that data is not only correct but that it is the right data for the task at hand

- To limit downstream costs, implement the mechanism to allow the uplink of any GNC parameter; procedures can control which parameters are available/authorized for uplink 


\section{Conclusions}

- The AFD team has contributed to Space Shuttle Program (SSP) success via innovation and sustained reliability

- Incremental evolution of ascent flight operations through 30 years and 135 flights

- Strategic initiatives helped the SSP achieve the desired flexibility by moving critical work as late as possible and by reducing cycle times

- Change management processes ensured that AFD procedures, tools and training materials kept pace with the frequency and complexity of SSP updates

- Despite cost reductions and work content additions, AFD maintained the quality required of a human spaceflight program

- Successful ascent flight operations can be attributed to the same safety culture that has been present in all US human spaceflight programs

- Challenges and mitigation strategies point to lessons learned that may apply to similar work on future programs 